\title{
Efficacy of zinc supplementation on growth and IGF-1 in prepubertal children with idiopathic short statures and low serum zinc levels
}

\author{
Kei Yoshida ${ }^{1}$, Tatsuhiko Urakami ${ }^{1}$, Yusuke Mine ${ }^{1}$, and Junichi Suzuki ${ }^{1}$ \\ ${ }^{I}$ Department of Pediatrics, Nihon University School of Medicine, Tokyo, Japan
}

\begin{abstract}
We investigated the effect of zinc supplementation on growth and serum IGF-1 levels in 10 prepubertal Japanese children with idiopathic short statures, who had serum zinc levels of less than $80 \mu \mathrm{g} / \mathrm{dL}$. Subjects were started on oral zinc supplementation at a dose of $25 \mathrm{mg}$ once daily. In three children, the doses were increased by $50 \mathrm{mg}$ once daily during the study period of $12 \mathrm{mo}$. The serum zinc levels rose in all subjects and reached a normal range (beyond 80 $\mu \mathrm{g} / \mathrm{dL}$ ). However, it was found that zinc supplementation did not promote growth. Although the mean IGF-1 standard deviations significantly increased, the majority did not reach the normal range. There were no significant adverse events other than mild gastrointestinal symptoms in 4 out of 10 subjects during the supplementation period. The most likely reason why growth was not promoted is that the zinc supplementation dosage was not enough to stimulate IGF-1 generation and subsequent growth velocity.
\end{abstract}

Key words: idiopathic short stature, IGF -1, Japanese children, growth, zinc

\section{Introduction}

Serum zinc can be reduced by low intake of zinc, malnutrition, malabsorption, liver dysfunction, chronic kidney disease, immune disorders, or drug-induced. Zinc deficiency is known to cause growth retardation, and it may be related to sexual development, immune resistance, infection susceptibility, appetite, taste, and memory (1-4). It is also known to interfere with the metabolism of the GH and impair growth during the neonatal to adolescent periods (5).

Several studies have demonstrated that short children, including those with idiopathic short statures without endocrine disorders, have high levels of zinc deficiency or low serum zinc levels (6-10). We found $48.3 \%$ of Japanese children with an idiopathic short stature had a low zinc level of $60-80 \mu \mathrm{g} / \mathrm{dL}$, and $6.7 \%$ had zinc deficiency with a zinc level of less than $60 \mu \mathrm{g} /$ dL. There was no significant correlation between serum zinc levels and age, standard deviation scores (SDSs) for height and serum IGF-1 levels in all subjects (11).

On the other hand, several studies reported the effectiveness of zinc supplementation on growth with increased serum levels of IGF-1 and/or IGF-bounding protein 3 (IGFBP3) in various groups of children with zinc deficiency (12-19). However, in some reports, growth promotion was not observed (20-22) or found only in boys (23). Furthermore, Baltaci AK et al. reported zinc levels decreased in hypothyroidism and increased in hyperthyroidism (24).

In the present study, we investigated the effect of zinc supplementation on growth and serum IGF-1 levels in prepubertal Japanese children with idiopathic short statures, who had low serum zinc levels.

\section{Subjects and Methods}

Study subjects included 10 Japanese children, of whom 6 were males, and 4 were females. They had a mean age of $7.2 \pm 1.2$ (range: $5.6-9.1 \mathrm{yr}$ old), had been diagnosed with an idiopathic short stature, and had a mean height of $-2.3 \pm 0.2(-2.1--2.5 \mathrm{SD})$. All subjects were prepubertal at Tanner stage 1 . All participants did not participate in physical training or club sports but did participate in physical education classes. Idiopathic short stature is defined as a height SDSs less than -2.0 SD without apparent endocrine disorders associated with short statures. None of the subjects had GH deficiency, defined as peak values of GH less than $6.0 \mathrm{ng} / \mathrm{mL}$ on any $\mathrm{GH}$ provocation test according to the diagnostic criteria

Received: January 8, 2020 Accepted: February 22, 2020

Corresponding author: Tatsuhiko Urakami, MD, PhD, Department of Pediatrics, Nihon University School of Medicine, 1-6 Kandasurugadai, Chiyoda-ku, Tokyo 101-8309, Japan

E-mail: urakami.tatsuhiko@nihon-u.ac.jp 
for GH deficiency by the Japan Society for Pediatric Endocrinology. None of the subjects had thyroid or sex hormone deficiencies, anemia, liver dysfunction, kidney dysfunction, and immunological disorders. Apparent nutritional or psychosocial problems were not observed. Five subjects were clinically diagnosed with familial short stature, 2 with intrauterine growth retardation, and 3 had unknown origins for their short stature. All subjects were identified with a low serum level of less than $80 \mu \mathrm{g} / \mathrm{dL}$, including the two subjects diagnosed with zinc deficiency with a serum zinc level less than $60 \mu \mathrm{g} /$ $\mathrm{dL}$ according to the diagnostic criteria of zinc deficiency reported by the Japanese Society of Clinical Nutrition (10). Subject characteristics at baseline are shown in Table 1.

Subjects were started on oral zinc supplementation (Nobelzin ${ }^{\circledR}$, Nobelpharma Co., Ltd., **located city, country**) at a dose of $25 \mathrm{mg}$ once daily. In three children aged over 8 yr old, the doses were increased by $50 \mathrm{mg}$ once daily, because of insufficient height gain, during the study period for 12 mo. We compared the serum zinc levels, height SDSs, IGF-1 SDSs for sex- and age-matched Japanese normal children $(25,26)$, and serum-free thyroxine (FT4) levels between the values at baseline and those at the $3^{\text {rd }}, 6^{\text {th }}$ and $12^{\text {th }}$ mo after starting zinc supplementation.

Anthropometric assessments and collection of serum samples were performed at the outpatient clinic of our hospital during the morning but not always after fasting. Serum zinc levels were measured by an absorption spectrophotometric method utilizing commercial kits (NIPRO Co., Ltd., Osaka, Japan). Serum IGF-1 levels were measured by an immune radiometric assay using commercial kits (Fujirebio Inc, Tokyo, Japan). Serum FT4 levels were measured by a chemiluminescence immunoassay utilizing Architect I 2000 (Abbott Laboratories, Chicago, USA; normal range $0.8-1.5 \mathrm{ng} / \mathrm{dL})$.

\section{Statistical analysis}

The results are expressed as means \pm SDSs. The Wilcoxon signed-rank test was used to evaluate the statistical differences between the two results. A oneway repeated-measures analysis of variance (ANOVA) with the Greenhouse-Geisser correction was used to evaluate statistical differences in the mean values. Posthoc multiple comparisons were used to evaluate changes in the mean values from the baseline using Dunnett's method. A $p$-value of $<0.05$ was considered statistically significant. All statistical analyses were conducted with SPSS, version 23.0 (IBM Corp, Armonk, NY, USA).

\section{Ethical considerations}

This study was approved by the Ethical Committee of Nihon University Hospital (No. 20180703).

This study was performed according to the Helsinki Declaration. All subjects provided informed consent to participate in the study.

\section{Results}

Changes in serum zinc levels at baseline, and the $3^{\text {rd }}, 6^{\text {th }}$ and $12^{\text {th }}$ mo after starting zinc supplementation

Initially, basal serum zinc levels in all subjects were below $80 \mu \mathrm{g} / \mathrm{dL}$, with a mean value of $67.2 \pm 6.1(57-76)$ $\mu \mathrm{g} / \mathrm{dL}$. After the supplementation of zinc, the serum zinc levels rose in all subjects and reached a normal range (beyond $80 \mu \mathrm{g} / \mathrm{dL}$ ). The mean values at the $3^{\text {rd }}, 6^{\text {th }}$ and $12^{\text {th }}$ mo $(93.3 \pm 5.6,106.9 \pm 10.3$ and $108.8 \pm 8.69 \mu \mathrm{g} / \mathrm{dL}$, respectively) were significantly higher than at baseline ( $p<0.01$, respectively) (Fig. 1).

\section{Changes in height SDSs at baseline, and the $3^{\text {rd }}, 6^{\text {th }}$ and $12^{\text {th }}$ mo after starting zinc supplementation}

The mean value of height SDSs at baseline was $-2.3 \pm 0.2$ SDSs. There was no significant increase in the mean height SDSs after zinc supplementation (at $3^{\text {rd }}, 6^{\text {th }}$, and $12^{\text {th }}$ mo: $-2.2 \pm 0.2,-2.2 \pm 0.2$ and $-2.3 \pm 0.2$ SDSs, respectively) (Fig. 2).

Table 1. Subject characteristics at baseline

\begin{tabular}{cccccccc}
\hline Case & Sex & Age $(\mathrm{yr})$ & Zn $(\mu \mathrm{g} / \mathrm{dL})$ & height SDS & \% over weight* & IGF-1 SDS & FT4 (ng/dL) \\
\hline 1 & M & 8.4 & 69 & -2.1 & -0.5 & -0.5 & 1.05 \\
2 & M & 9.1 & 70 & -2.1 & -3.8 & -1.1 & 0.98 \\
3 & F & 5.9 & 68 & -2.3 & -0.8 & -1.8 & 1.12 \\
4 & M & 5.6 & 70 & -2.3 & -8.3 & -0.8 & 0.95 \\
5 & M & 8.9 & 64 & -2.1 & 1.8 & 0.1 & 0.93 \\
6 & M & 7.2 & 76 & -2.6 & -0.9 & -1.87 & 1.09 \\
7 & F & 8.3 & 74 & -2.5 & -3.7 & -1.55 & 1.09 \\
8 & M & 6.3 & 59 & -2.4 & 0.2 & -0.9 & 1.99 \\
9 & F & 5.7 & 65 & -2.3 & -6.6 & -0.2 & 1.05 \\
10 & F & 7.5 & 57 & -2.1 & 0.4 & \\
\hline
\end{tabular}

*\% overweight was calculated as follows: (current weight-ideal weight*)/ ideal weight $\times 100$. 


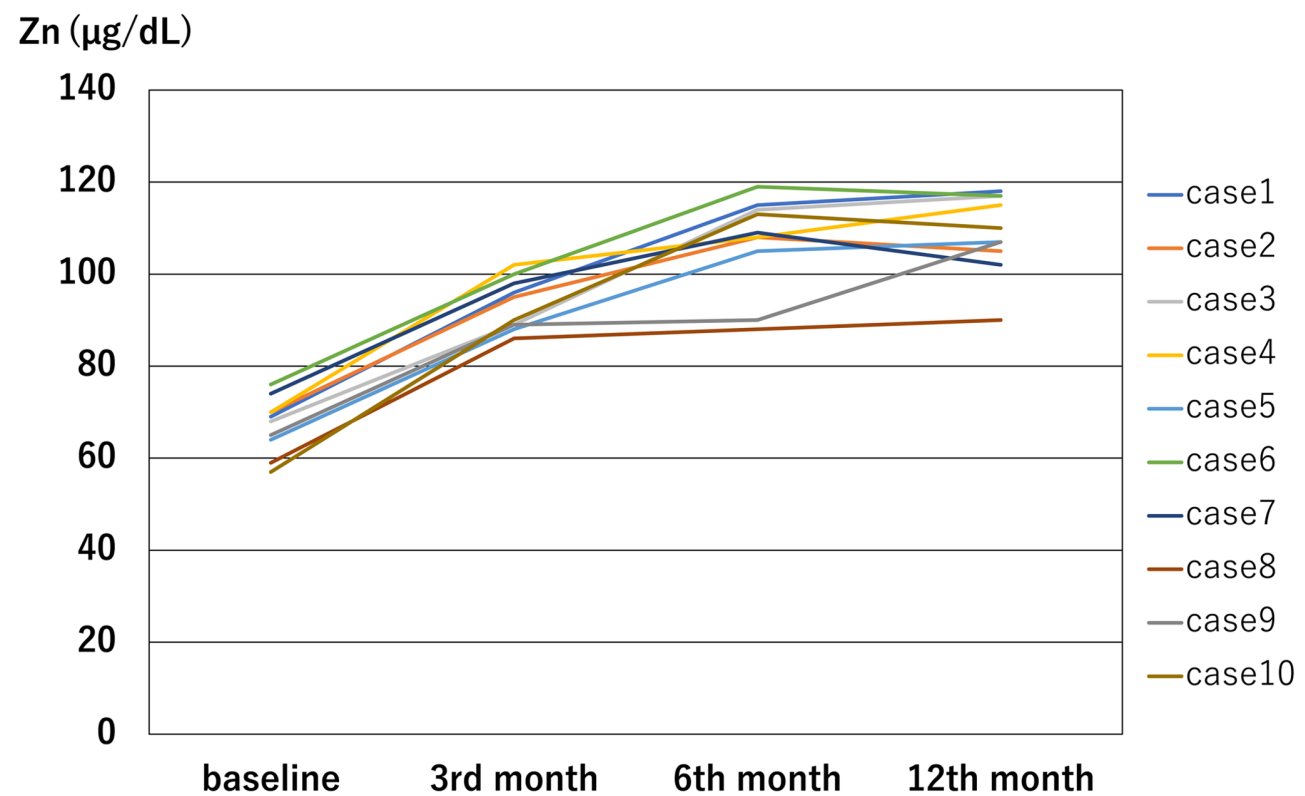

Fig. 1. Changes in the serum zinc levels at baseline, and at the $3^{\text {rd }}, 6^{\text {th }}$, and $12^{\text {th }}$ mo after starting zinc supplementation.

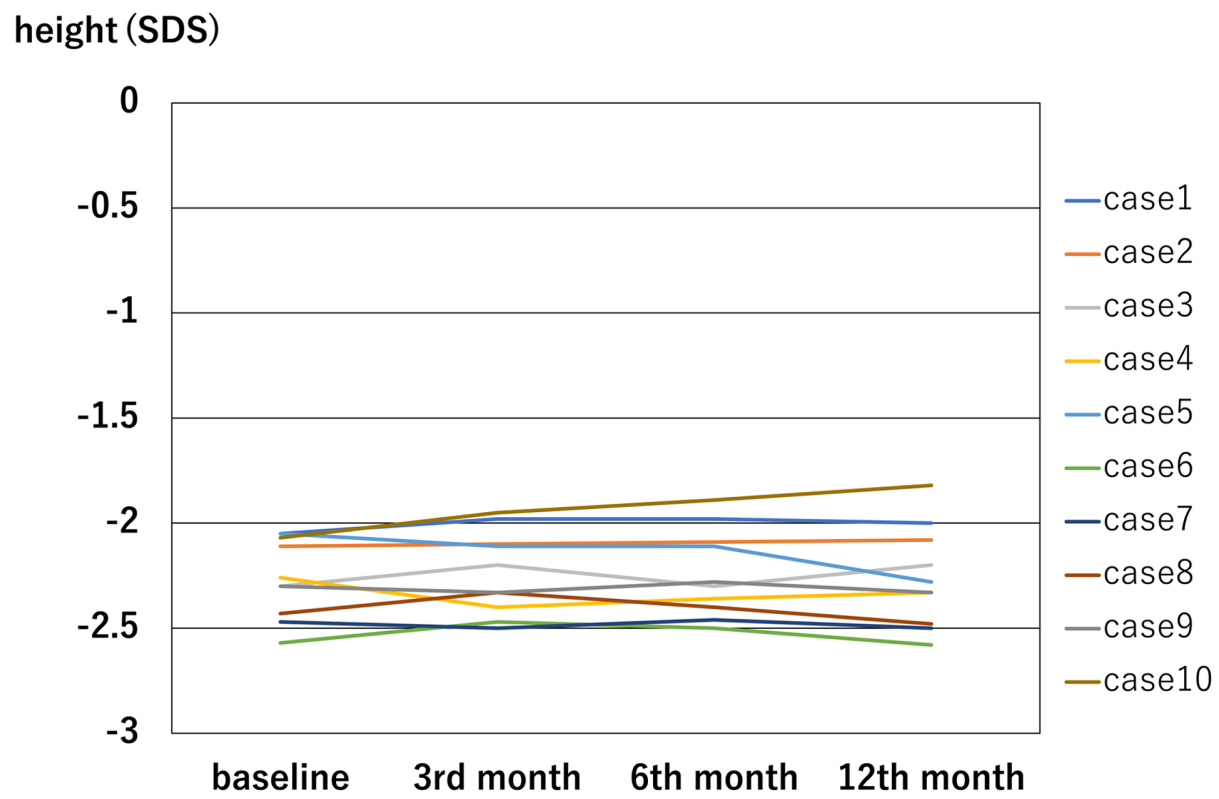

Fig. 2. Changes in the height standard deviation scores (SDSs) at baseline, and at the $3^{\text {rd }}, 6^{\text {th }}$, and $12^{\text {th }}$ mo after starting zinc supplementation.

\section{Changes in IGF-1 SDSs and serum FT4 levels at baseline, and the 3rd, 6th and 12th mo after starting zinc supplementation}

The mean IGF-1 SDSs at baseline was $-0.9 \pm 0.7$ SD. Those at the $3^{\text {rd }}, 6^{\text {th, }}$ and $12^{\text {th }}$ mo $(-0.7 \pm 0.6,-0.6 \pm$ 0.7 and $0.6 \pm 0.7 \mathrm{SDSs}$, respectively) were significantly higher than at baseline ( $p<0.05$, respectively) (Fig. 3). However, only 2 subjects achieved IGF-1 SDSs beyond $-0.0 \mathrm{SD}$ in a normal reference range $(25,26)$. On the other hand, the mean FT4 levels did not change during the study period (at baseline, and the $3^{\text {rd }}, 6^{\text {th }}$ and $12^{\text {th }}$ mo: $1.0 \pm 0.1,1.0 \pm 0.1,1.1 \pm 0.1$ and $1.1 \pm 0.1 \mathrm{ng} / \mathrm{dL}$, respectively) (Fig. 4).

There were no significant adverse events other than mild gastrointestinal symptoms, including nausea, abdominal disturbance, and appetite loss, in 4 out of 10 subjects during the supplementation period. Anemia, neutropenia, liver dysfunction, and kidney disfunction were not observed.

\section{Discussion}

Zinc deficiency is widespread throughout the world, in both developing and developed countries. Hamsa et al. (18) indicated that growth retardation due to zinc 


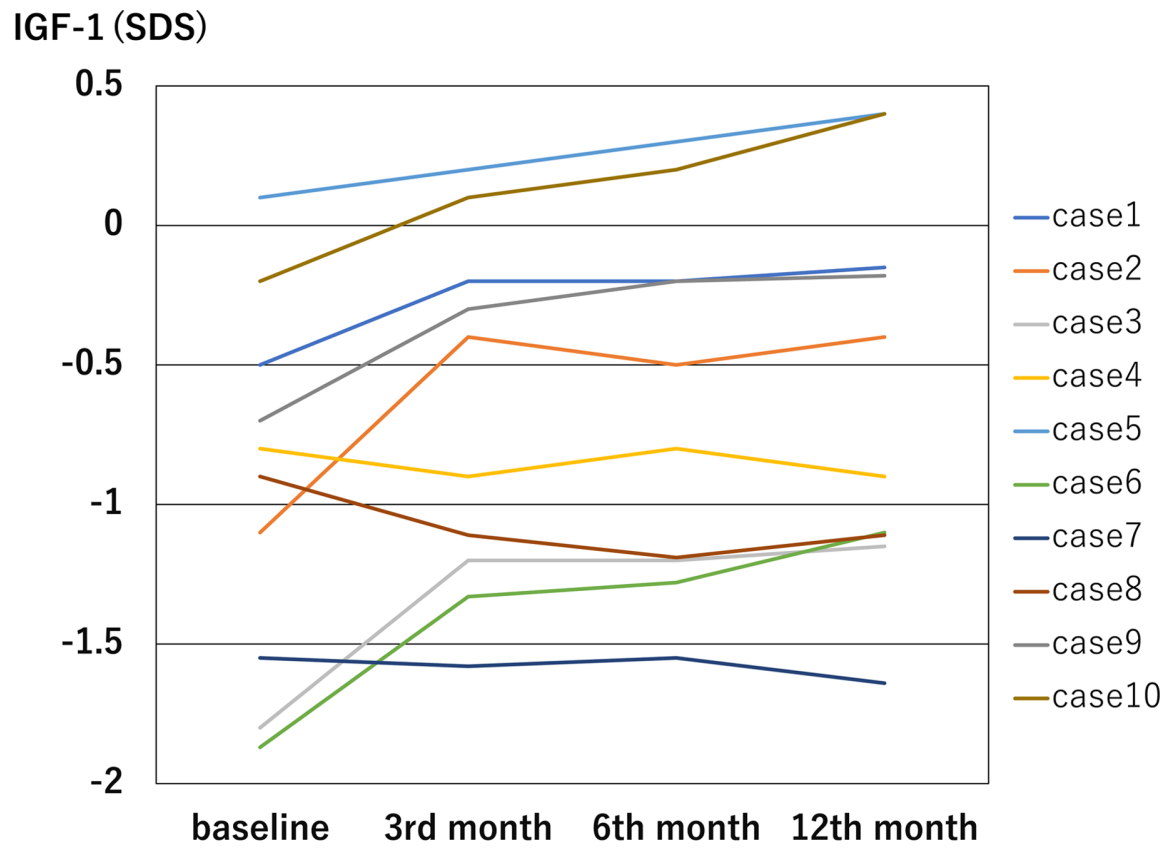

Fig. 3. Changes in the IGF-1 standard deviation scores (SDSs) at baseline, and at the $3^{\text {rd }}, 6^{\text {th }}$, and $12^{\text {th }}$ mo after starting zinc supplementation.

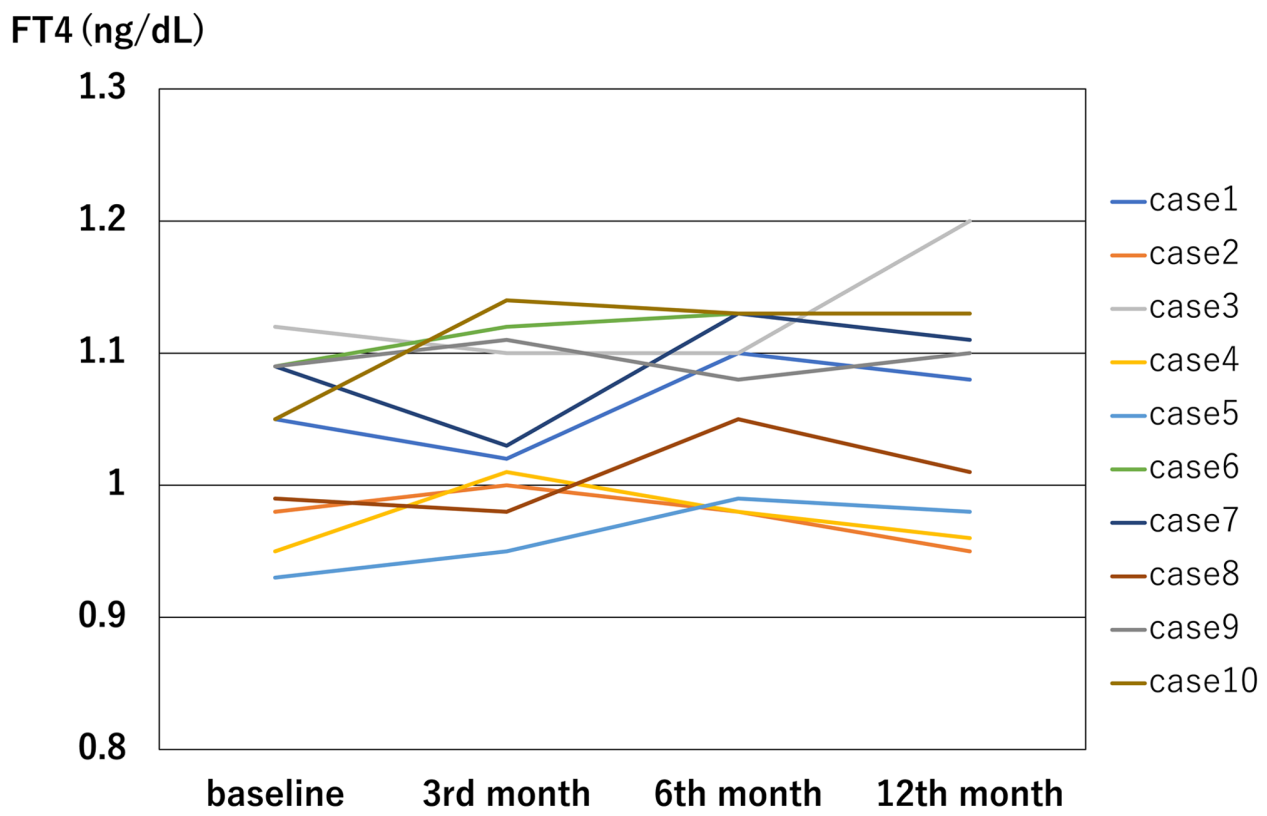

Fig. 4. Changes in the serum-free thyroxine (FT4) levels at baseline, and at the $3^{\text {rd }}, 6^{\text {th }}$, and $12^{\text {th }}$ mo after starting zinc supplementation.

deficiency is commonly observed in developing countries. However, several Japanese studies showed that the frequencies of zinc deficiency and/or a low serum zinc level were high in short Japanese children (7, 10, 11, 14), possibly due to inadequate dietary habits, such as a high intake of snacks and convenient food with a lower zinc content, which might influence growth retardation $(6,10)$.

Effectiveness of zinc supplementation on growth in short children with zinc deficiency or a low serum zinc level was demonstrated in several previous studies (12-19). Many of the studies also showed that zinc supplementation increased GH secretion, and IGF-1 as well as IGFBP-3 generation, leading to a promotion of growth (7, 13-16). Nishi et al. (7) reported that transient GH deficiency was a possible reason for growth retardation in children with zinc deficiency by reducing circulating IGF-1. Nakamura et al. (13) reported that zinc supplementation was effective for increasing growth velocity in short children compared to untreated 
children by a rise of serum IGF-1 levels. İmamoğlu et al. (16) demonstrated that zinc supplementation directly increased IGF-1 and IGFBP-3 generation, leading to improved growth velocity in children with idiopathic short statures. These findings suggest that zinc supplementation might be associated with the GHIGF- 1 axis, IGF-1, and IGFBP-3 generation, and could help to promote growth in short children.

In the present study, growth promotion was not observed, although the mean IGF-1 SDSs significantly increased after zinc supplementation, in Japanese children with idiopathic short statures. We also did not find an association between height velocities and any possible promoting factors, as proposed by previous reports, such as age and serum IGF-1 levels (12-19). Perhaps, in the current study, the zinc supplementation dosage was not enough to stimulate IGF-1 generation, which leads to increased growth velocity. The mean IGF-1 SDSs in the subjects did increase. However, case 5 had an IGF-1 SDSs beyond 0.0 SD at baseline, and cases 5 and 10 achieved IGF-1 SDSs beyond 0.0 SD even after zinc supplementation. Nobelzin ${ }^{\circledR}$ is recommended to be started at a daily dose of $25 \mathrm{mg}$, which can be increased to $75 \mathrm{mg}$ for children with zinc deficiency that are over $6 \mathrm{yr}$ old. The $25 \mathrm{mg}$ Nobelzin ${ }^{\circledR}$ dose was continued in 7 subjects throughout the study period. In 3 children over 8 years old, the dosage was increased by $50 \mathrm{mg}$ daily because of insufficient growth. However, zinc supplementation failed to promote growth in most subjects. The 3 children with an increased dose also did not show improvements in height velocity and \% overweight (data not shown). These applied dosages of zinc might be insufficient to promote growth in children with idiopathic short statures and low zinc levels.

There were several limitations to this study. First, we did not investigate the eating habits of each subject. No unbalanced diet habits were observed when a medical history was taken from family members of the subjects. However, a more detailed investigation may be necessary to find the cause of the low serum zinc levels in the subjects. Second, we measured serum zinc levels during the morning, but not always after fasting (27). Therefore, the serum zinc levels could be lower than the actual zinc levels measured in a fasting state. Third, the number of subjects studied was small. The number of subjects should be increased to confirm the results.

In conclusion, we found that zinc supplementation did not promote growth in Japanese children with idiopathic short statures. Although the mean serum IGF-1 SDSs significantly increased, the majority of the IGF-1 SDSs did not reach a normal range. Perhaps, in the current study, the zinc supplementation dosage was not enough to stimulate IGF-1 generation, leading to increased growth velocity.

Conflict of interest: The authors have no conflicts of interest to declare in relation to this study.

\section{References}

1. Prasad AS. Discovery and importance of zinc in human nutrition. Fed Proc 1984;43: 2829-34. [Medline]

2. Hambidge KM, Silverman A. Pica with rapid improvement after dietary zinc supplementation. Arch Dis Child 1973;48: 567-8. [Medline] [CrossRef]

3. Prasad AS. Clinical manifestations of zinc deficiency. Annu Rev Nutr 1985;5: 341-63. [Medline] [CrossRef]

4. Laitinen R, Vuori E, Dahlström S, Akerblom HK. Zinc, copper, and growth status in children and adolescents. Pediatr Res 1989;25: 323-6. [Medline] [CrossRef]

5. Prasad AS. Clinical, endocrinological and biochemical effects of zinc deficiency. Clin Endocrinol Metab 1985;14:567-89. [Medline] [CrossRef]

6. Nishi Y. Zinc levels in plasma, erythrocyte and leukocyte in healthy children and adults. Hiroshima J Med Sci 1980;29: 7-13. [Medline]

7. Nishi Y, Hatano S, Aihara K, Fujie A, Kihara M. Transient partial growth hormone deficiency due to zinc deficiency. J Am Coll Nutr 1989;8: 93-7. [Medline] [CrossRef]

8. Nishi Y. Zinc and growth. J Am Coll Nutr 1996;15: 340-4. [Medline] [CrossRef]

9. Kurosawa R, Kubori S. Zinc deficiency and its clinical features in the cases found in Kitamimaki, a rural area in Japan. Biomed Res Trace Elements 2006;17: 91-3.

10. Kodama H, Itakura H, Omori K, Sasaki M, Santo K, Takamura T, et al. Clinical guideline for zinc deficiency. J Japan Soc Clin Nutr 2016;38: 104-48 (in Japanese).

11. Yoshida K, Urakami T, Kuwabara R, Morioka I. Zinc deficiency in Japanese children with idiopathic short stature. J Pediatr Endocrinol Metab 2019;32: 1083-7. [Medline] [CrossRef]

12. Collipp PJ, Castro-Magana M, Petrovic M, Thomas J, Cheruvanky T, Chen SY, et al. Zinc deficiency: improvement in growth and growth hormone levels with oral zinc therapy. Ann Nutr Metab 1982;26: 287-90. [Medline] [CrossRef]

13. Nakamura T, Nishiyama S, Futagoishi-Suginohara Y, Matsuda I, Higashi A. Mild to moderate zinc deficiency in short children: effect of zinc supplementation on linear growth velocity. J Pediatr 1993;123: 65-9. [Medline] [CrossRef]

14. Kaji M, Gotoh M, Takagi Y, Masuda H, Kimura Y, Uenoyama Y. Studies to determine the usefulness of the zinc clearance test to diagnose marginal zinc deficiency and the effects of oral zinc supplementation for short children. J Am Coll Nutr 1998;17: 388-91. [Medline] [CrossRef]

15. Penny ME, Marin RM, Duran A, Peerson JM, Lanata CF, Lönnerdal B, et al. Randomized controlled trial of the effect of 
daily supplementation with zinc or multiple micronutrients on the morbidity, growth, and micronutrient status of young Peruvian children. Am J Clin Nutr 2004;79: 457-65. [Medline] [CrossRef]

16. Imamoğlu S, Bereket A, Turan S, Taga Y, Haklar G. Effect of zinc supplementation on growth hormone secretion, IGF-I, IGFBP-3, somatomedin generation, alkaline phosphatase, osteocalcin and growth in prepubertal children with idiopathic short stature. J Pediatr Endocrinol Metab 2005;18: 69-74. [Medline] [CrossRef]

17. Cesur Y, Yordaman N, Doğan M. Serum insulin-like growth factor-I and insulin-like growth factor binding protein-3 levels in children with zinc deficiency and the effect of zinc supplementation on these parameters. J Pediatr Endocrinol Metab 2009;22: 1137-43. [Medline] [CrossRef]

18. Hamza RT, Hamed AI, Sallam MT. Effect of zinc supplementation on growth hormone-insulin growth factor axis in short Egyptian children with zinc deficiency. Ital J Pediatr 2012;38: 21. [Medline] [CrossRef]

19. Brown KH, Peerson JM, Rivera J, Allen LH. Effect of supplemental zinc on the growth and serum zinc concentrations of prepubertal children: a meta-analysis of randomized controlled trials. Am J Clin Nutr 2002;75: 1062-71. [Medline]

20. Friis H, Ndhlovu P, Mduluza T, Kaondera K, Sandström B, Michaelsen KF, et al. The impact of zinc supplementation on growth and body composition: a randomized, controlled trial among rural Zimbabwean schoolchildren. Eur J Clin Nutr 1997;51: 38-45. [Medline] [CrossRef]

21. Hershkowitz E, Printzman L, Segev Y, Levy J, Philip M. Zinc supplementation increases the level of serum insulin-like growth factor-I but does not promote growth in infants with nonorganic failure to thrive. Horm Res 1999;52: 200-4. [Medline]

22. Bouglé D, Laroche D, Bureau F. Zinc and iron status and growth in healthy infants. Eur J Clin Nutr 2000;54: 764-7. [Medline] [CrossRef]

23. Castillo-Durán C, García H, Venegas P, Torrealba I, Panteón E, Concha N, et al. Zinc supplementation increases growth velocity of male children and adolescents with short stature. Acta Paediatr 1994;83: 833-7. [Medline] [CrossRef]

24. Baltaci AK, Mogulkoc R. Leptin, NPY, Melatonin and Zinc Levels in Experimental Hypothyroidism and Hyperthyroidism: The Relation to Zinc. Biochem Genet 2017;55: 223-33. [Medline] [CrossRef]

25. Isojima T, Kato N, Ito Y, Kanzaki S, Murata M. Growth standard charts for Japanese children with mean and standard deviation (SD) values based on the year 2000 national survey. Clin Pediatr Endocrinol 2016;25: 71-6. [Medline] [CrossRef]

26. Isojima T, Shimatsu A, Yokoya S, Chihara K, Tanaka T, Hizuka N, et al. Standardized centile curves and reference intervals of serum insulin-like growth factor-I (IGF-I) levels in a normal Japanese population using the LMS method. Endocr J 2012;59: 771-80. [Medline] [CrossRef]

27. McMillan EM, Rowe DJF. Clinical significance of diurnal variation in the estimation of plasma zinc. Clin Exp Dermatol 1982;7: 629-32. [Medline] [CrossRef] 